\title{
Evaluation of Treatment and Management of Corneal Bacterial Ulcers - A Cross Sectional Study from Saudi Arabia
}

\author{
Yaser M Alahmadi ${ }^{1}$, Athar Ahmed Faidh ${ }^{2}$, Raneem Ahmed Faidh ${ }^{3}$, Sumaiyah Masoud Alrehaili' ${ }^{2}$, Omar Mahmoud Alabbasi ${ }^{3}$, \\ Rafif Y Aalahmadi ${ }^{3}$, Rahmah Yasin Azzouni ${ }^{2}$, Mansour A Mahmoud ', Ali Alalawi ${ }^{2}$, Hossein Mostafa Elbadawy ${ }^{2, *}$ \\ 'Department of Clinical and Hospital Pharmacy, College of Pharmacy, Taibah University, Almadinah Almunawwarah, KINGDOM OF SAUDI ARABIA \\ 2Department of Pharmacology and Toxicology, College of Pharmacy, Taibah University, Almadinah Almunawwarah, KINGDOM OF SAUDI ARABIA. \\ ${ }^{3}$ College of Medicine, Taibah University, Almadinah Almunawwarah, KINGDOM OF SAUDI ARABIA.
}

\begin{abstract}
Objectives: To study the current practice patterns and opinions in the treatment of corneal bacterial ulcers among Saudi ophthalmologists. Methods: A web-based online survey was conducted in Saudi Arabia to randomly selected ophthalmologists who were registered with Saudi commission for health specialties during the study period between August 2018 to December 2018 using a structured self-administered questionnaire. Results: Of the respondents, general ophthalmologists were $32(58.2 \%)$ and cornea specialists were $23(41.8 \%)$. The mean years of practice was $6.6 \pm 6.1[$ mean $\pm S D$ ]. Among the respondents $53(96.4 \%)$ treated corneal ulcer cases, most of them 51 (92.7\%) agreed there is a relation between the use of contact lenses and ocular ulcers. Fifty respondents indicated that they prescribed antibiotics for the treatment of corneal ulcer. About 12 (52.2\%) of the cornea specialist and 22 (68.8\%) of general ophthalmologists prefer to use culture of ulcer (Scrapping and gram staining of ulcer) diagnostic tests prior to treatment of corneal ulcers. Fortified antibiotic used was given higher advantage and the management
\end{abstract}

of ocular ulcers differed according to the severity of each case. Conclusion: In conclusion, results found that the management of corneal ulcers varies from specialist to general ophthalmologist. All the respondents agreed that they prescribed two broad spectrum antibiotics to treat an advanced corneal ulcer. Additionally, most of the respondents believed that fourth generation fluoroquinolones were less effective in comparison to fortified, broad-spectrum antibiotics.

Key words: Corneal bacterial ulcers, Antibiotics, Fluoroquinolones, Broad spectrum antibiotics, Fortified antibiotics.

Correspondence

Dr. Yaser M Alahmadi

Department of Clinical and Hospital Pharmacy, College of Pharmacy, Taibah University, Almadinah Almunawwarah, KINGDOM OF SAUDI ARABIA.

Email: yalahmadi45@gmail.com

DOI: 10.5530/jyp.2021.13.30

\section{INTRODUCTION}

Corneal bacterial ulcer is a serious eye infection that requires an early diagnosis, as well as an immediate and adequate treatment and is a significant cause of visual impairment and blindness among individual's patients. ${ }^{1-3} \mathrm{~A}$ corneal ulcer is an open sore or epithelial defect with underlying inflammation of the cornea, responsible for a large proportion of post-surgery complications and severe scarring. ${ }^{2}$ In many occasions, corneal scars can cause irreversible loss of clear vision, sometimes it is allergic in nature, or it can be caused by endogenous infections ${ }^{4}$ or due to autoimmune disorders. ${ }^{5}$ However, the corneal disease remains the leading cause of monocular blindness worldwide, especially affecting marginalized populations. ${ }^{2}$ In addition, the World Health Organization (WHO) considered this disease as the main public health problem in developing countries. ${ }^{6}$ According to WHO, there are about 710 corneal ulcers per 100,000 populations annually. ${ }^{6}$ In India alone approximately 2 million people develop corneal ulcers every year. ${ }^{2}$

Infectious keratitis is linked to specific predisposing elements, such as poor social and economic factors including illiteracy and malnutrition. ${ }^{7}$ Globally it is estimated that ocular trauma and corneal ulceration, result in 1.5 to 2 million new cases of corneal blindness annually. ${ }^{5}$ Risk factors for bacterial keratitis include the use of contact lenses, physical or chemical trauma, corneal epithelial diseases, specific surgeries and immunodeficiency..$^{8-11}$

The complications of corneal ulceration may lead to corneal blindness or even corneal perforation, which cannot be considered uncommon.
Fungal keratitis is a main cause for corneal blindness in Asia responsible for around 44 percent of central corneal ulcer. However, $60-70 \%$ of corneal scars or adherent Leucoma are caused by corneal ulcers which were not managed correctly, as indicated in a study carried out in India. ${ }^{12}$ Organisms that introduce changes to the normal bacterial flora of the eye, such as Streptococci and Staphylococci, can defeat the defense mechanisms and cause ulceration of the cornea. ${ }^{13,14}$ Right diagnosis of keratitis is important for defining an effective therapeutic plan and to control the infection. The gold standard in diagnosis remains Gram stain and culture of corneal samples despite drawbacks of this traditional method. ${ }^{15}$ Determining the best treatment depends on the causative organism; however, Gram stain and culture results are usually delayed for hours and up to days, and therefore, empirical treatment is commonly started beforehand. ${ }^{16}$ Topical antibiotics remain the best treatment for bacterial keratitis, and a recent review found all commonly prescribed topical antibiotics to be comparably effective. ${ }^{17}$ There has been debate about the use of commercially available fourth-generation fluoroquinolones versus compounded fortified antibiotics such as vancomycin and tobramycin for the initial treatment of bacterial corneal ulcers. ${ }^{16,17}$ In the United States, where bacterial resistance is rather a more complicated problem than in the developing world, fortified antibiotics have a light advantage. ${ }^{18,19}$ In general, bacterial ulcers are usually responsive to treatment with available topical antibiotic drops, an increase in the rates of antibiotic-resistant infections such as methicillin-

This is an open access article distributed under the terms of the Creative Commons Attribution-NonCommercial-ShareAlike 4.0 License, which allows others to remix, tweak, and build upon the work non-commercially, as long as the author is credited and the new creations are licensed under the identical terms. 
resistant Staphylococcus aureus (MRSA) in the first world are causing problems, as reported in the antibiotic resistance report performed by the Euro surveillance team. ${ }^{20}$ Several randomized controlled trials have shown equivalency between the fluoroquinolones and fortified antibiotics. ${ }^{3}$ Surveying several research articles, it was concluded that fluoroquinolones are the first choice for empirical treatment of bacterial keratitis, however, combined fortified antibiotics were also sufficiently effective. ${ }^{21}$ This study was designed to explore the opinions of ophthalmologists regarding the management of ocular ulcers, including their approach to treatment using antibiotics and the first choice of antibiotic for several given conditions.

\section{SUBJECTS AND METHODS}

A web-based cross sectional, nationwide survey of ophthalmologist conducted between 2018 to 2019 . The study included randomly selected ophthalmologist from all the regions of Saudi Arabia including. We included ophthalmologists currently working in Saudi Arabia.

The questionnaire was prepared from extensive review of the literature published in this regard..$^{18}$ The questionnaire for this study composed of following group of variables, which include demographics such as region of practice, years of practice, specialties, number of corneal ulcer patients visit, Relation between the use of contact lenses and ocular ulcers, usual prescription for the ulcer patients. Second part of the questionnaire asked about Frequency of treating corneal ulcers, testing performed before treating corneal ulcers, and Frequency of corneal ulcers that were initially therapy-resistant and consisted of total of 4 questions. Thirdly it asks about opinions on the need for culturing corneal ulcers drugs of choices and dosing frequency of the antibiotics for the treatment of corneal ulcers. The questionnaire included both multiple choices and binary answer type questions. To check the validity of the questionnaire pilot study was conducted among randomly selected 3 ophthalmologists a Cronbach alpha value of 0.70 found appropriate for the study. The participants contact details were obtained from the Saudi commission for health specialty. An electronic survey designed on Google forms, an online survey tool, was e-mailed in august 2018 to randomly selected ophthalmologists, whose contact information was obtained from the Saudi Commission for the health specialties, Riyadh Saudi Arabia. The participants were sent reminders to fill and send back the surveys, to get accurate responses; reminders were sent after every two weeks to get accurate response rate. The incomplete responses and unrecognized emails and non- responders were excluded from the study.Data were anonym zed (i.e., personal information like names and addresses were removed). A unique identifier was assigned for data analysis. The data were analyzed using Statistical Package for Social Science (SPSS) Version 26 for Windows. Descriptive statistics included percentages and frequency distributions were calculated results were presented in mean \pm standard deviation (SD).

\section{RESULTS}

A total of 150 surveys were distributed, 33 questionnaires failed recognize the email address of the recipient and therefore returned back to the researchers, and $62(41 \%)$ responses were found incompletely answered, therefore were excluded from the study. Of the 150 surveys that were sent online, 55 questionnaires were completely answered, giving a response rate of $36.6 \%$. Participants were selected randomly from 11 cities around Saudi Arabia and were either general ophthalmologists or specialized in cornea, retina or refractive surgery. Of the submitted surveys, General ophthalmologists were 32(58.2\%), Cornea specialists 23(41.8\%). Half of the surveyed respondents were from the central region of Saudi Arabia $27(49.1 \%)$, while the rest were from the other regions. The minimum number of years in practice was one year and the maximum was 28 years with a mean of $6.6 \pm 6.1$ [mean $\pm \mathrm{SD}$ ] years. Among the subjects almost all 53(96.4\%) respondents treated corneal ulcers. Additionally, the majority of them $51(91.1 \%)$ agreed that there is a relation between the use of contact lenses and ocular ulcers. Fifty respondents indicated that they prescribed Antibiotics for corneal ulcer patients, while $3(5.4 \%)$ of the respondents prefer to prescribe lubricants. Further, detailed information of the responses is given in Table 1.

With regards to the number of patients requiring bacterial cultures the average was 5.2 patients with cornea specialists per month, while with general ophthalmologists the average number of patients was $3.7 \pm 3.6$ [mean $\pm S D]$. An average of 6.3 patients per month, according to cornea specialists, required asking for gram stain. In addition, on average of 14.5 patients managed by cornea specialists reported resistance to initial therapy in comparison to $10.93 \pm 11.67$ [mean $\pm \mathrm{SD}$ ] patients managed by general ophthalmologists. About $12(52.2 \%)$ of cornea specialists and $22(68.8 \%)$ of general ophthalmologists preferred to use cultures of ulcer (Scrapping and gram staining of ulcer) diagnostic tests prior to treatment of corneal ulcers, while 7 (30.4\%) of cornea specialists and 4 (12.5\%) of general ophthalmologists reported the use of scrapping and gram staining of ulcers as diagnostic tests (Table 2).

A good majority of the respondents in both categories were reported to have a pharmacy at their workplace capable of compounding antibiotic preparations. With regards to opinions about the need for culturing corneal ulcers $25.4 \%$ of total respondents indicated that culturing corneal ulcers is always necessary (Table 3 ). Both non-cornea specialists, and cornea specialists specified that culturing is necessary for ulcers larger than $1.5 \times 1.5 \mathrm{~mm}$, regardless of the location (7 (30.4\%) vs. $7(21.8 \%)$ ). Compared to general ophthalmologists, a greater number of cornea specialists stated that culturing is necessary for ulcers unresponsive to antibiotic therapy $4(17.3 \%)$ vs 0 . However, both categories of ophthalmologists agreed that culturing is necessary for ulcers larger than 1.5.1.5 mm, within the central $5 \mathrm{~mm}$ of the cornea (Table 3).

Study results shows that drug therapy for the treatment of corneal ulcers consisted of two treatment tiers. For the mild corneal ulcers $60 \%$ of the all respondents stated that they would use fluoroquinolones such as Moxifloxacin (39.3\%) followed by Gatifloxacin (12.5\%). The next most common choice among the respondents was 2 broad spectrum antibiotics, which includes cefazoline and gentamycin $(18 \%$ of the respondents). (Figure 1). Regarding the First choice of antibiotics to treat an advanced corneal ulcer, $70.1 \%$ of the respondents would prefer

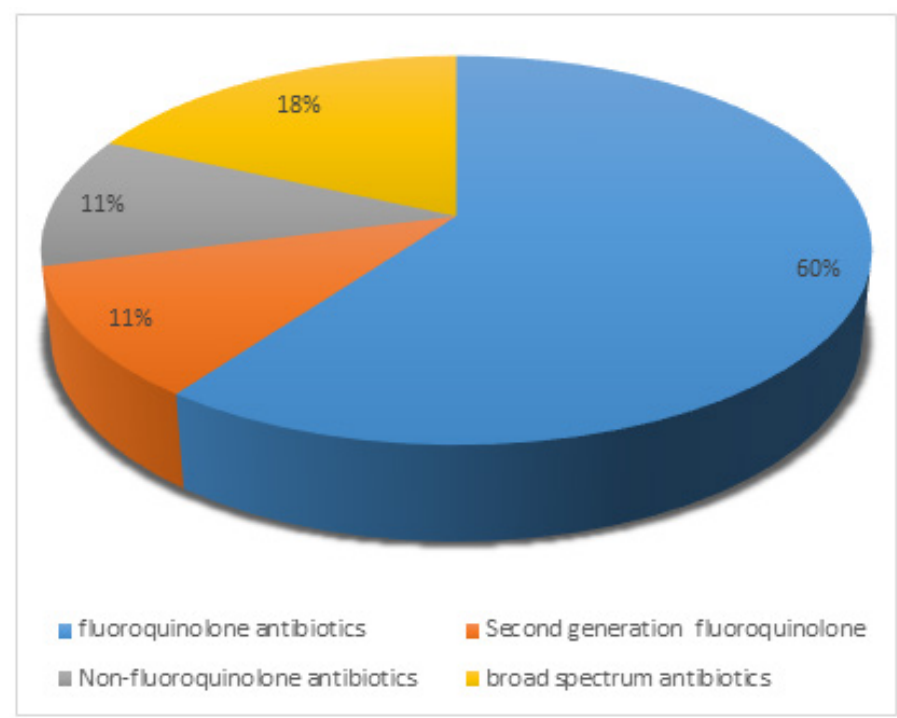

Figure 1: Shows the Initial choice of antibiotics to treat a mild corneal ulcer. 
to use 2 broad spectrum antibiotics (Cefazoline and Gentamicin). The second choice among participants was Moxifloxacin (9.1\%) followed by Cefazoline and other combinations (9.1\%), Non-fluoroquinolone antibiotics (Tobramycin or Gentamicin) (7.2\%) and Gatifloxacin (3.6\%). In terms of effectiveness the comparison between fourth generation fluoroquinolones and dual, fortified, broad-spectrum antibiotics for the treatment of severe corneal ulcers, most of the respondents (64.3\%) believed that fourth generation fluoroquinolones were less effective in comparison to fortified, broad-spectrum antibiotics. However, about $20 \%$ of the respondents also believed that fourth generation fluoroquinolones are as effective as fortified antibiotics, while only $14.3 \%$ of them stated that fourth generation fluoroquinolones are better and more efficacious compared to fortified antibiotics. The detailed description of the responses is given in Table 4 .

With regards to dosing frequency for the prescription of initial choice of antibiotics $33.4 \%$ of the respondents sated chose 'every $1 \mathrm{hr}$ during day and night', $28.6 \%$ recommended the administration of antibiotics every $1 \mathrm{hr}$ during the day, followed by a less number (18\%) who selected 'every 6 hr', while 'every 2 hr during the day' was selected by $16.1 \%$ of the respondents. For the prescription of antibiotic more than half (57.1\%) of the respondents indicated that dosing frequency would be every $1 \mathrm{hr}$ during day and night, and the second most selected choice (18\%) was 'every 1 hr during the day'. More details are given in Figure 2.

\section{DISCUSSION}

Studies on the evaluation of treatment options and opinions in the management of ophthalmologist corneal bacterial ulcers are limited. To the best of our knowledge, this is the first study which evaluate

Table 1: Survey demographics with some statements.

\begin{tabular}{|c|c|}
\hline Characters & n (\%) \\
\hline Total responses & 55 \\
\hline \multicolumn{2}{|l|}{ Category of the ophthalmologist } \\
\hline General ophthalmologists & $32(58.2 \%)$ \\
\hline Cornea specialists & $23(41.8)$ \\
\hline \multicolumn{2}{|c|}{ Geographic area of practice, all respondents } \\
\hline Central & $27(49.1)$ \\
\hline East & $14(25.1)$ \\
\hline West & $14(25.1)$ \\
\hline Number of years in practice & $6.6(\mathrm{SD}=6.1)$ \\
\hline \multicolumn{2}{|c|}{ Whether respondents treat corneal ulcers in practice } \\
\hline Yes & $53(96.4)$ \\
\hline No & $2(3.6)$ \\
\hline \multicolumn{2}{|c|}{$\begin{array}{l}\text { On average how many corneal ulcer patients do you see per } \\
\text { month }\end{array}$} \\
\hline General ophthalmologists $(\mathrm{n}=32)$ & $6.0(\mathrm{SD}=8.45)$ \\
\hline Cornea specialists (23) & $6.8(\mathrm{SD}=6.4)$ \\
\hline \multicolumn{2}{|c|}{ Relation between the use of contact lenses and ocular ulcers } \\
\hline Yes & $51(91.1)$ \\
\hline No & $4(7.2)$ \\
\hline \multicolumn{2}{|c|}{ For corneal ulcer patients, you usually start with prescribing } \\
\hline Antibiotics & $50(89.3)$ \\
\hline Anticholinergic & $1(1.8)$ \\
\hline Lubricant & $3(5.4)$ \\
\hline Steroids & $1(1.8)$ \\
\hline
\end{tabular}

ophthalmologist' knowledge of treatment and opinions about drug use in bacterial ulcers. This study found that $91 \%$ of the respondents agreed that a relation between the use of contact lenses and ocular ulcers. Although similar findings were reported by number of previous studies, ${ }^{22-26}$ for example a study by Reddy et al. in 2008 reported that $78.9 \%$ of contact lenses users suffered from corneal ulcer with positive organism cultures. The contact lenses nowadays were very common and popular among individuals for the sake of beautifying the look as well as for therapeutic purposes. Although use contact lenses were found to be associated with high risk of corneal ulceration than in non- users in a number of studies around the world. ${ }^{22,24-26}$

Table 2: Shows the Responses Listing the Frequency of Treating Corneal Ulcers, Testing Performed before Treating Corneal Ulcers, and Frequency of Corneal Ulcers That Were Initially Therapy-Resistant.

\begin{tabular}{|c|c|c|}
\hline Statements & $\begin{array}{l}\text { Cornea } \\
\text { specialists }\end{array}$ & $\begin{array}{c}\text { General } \\
\text { ophthalmologists }\end{array}$ \\
\hline $\begin{array}{l}\text { How many of corneal ulcers patients } \\
\text { (per month) requires asking for } \\
\text { bacterial culture? }\end{array}$ & $\begin{array}{c}5.2 \pm 5.4 \\
{[\text { mean } \pm \mathrm{SD}]}\end{array}$ & $\begin{array}{c}3.7 \pm 3.6 \\
{[\text { mean } \pm \mathrm{SD}]}\end{array}$ \\
\hline $\begin{array}{l}\text { How many of corneal ulcer patients } \\
\text { (per month) require asking for a } \\
\text { gram stain }\end{array}$ & $\begin{array}{c}6.39 \pm 12.1 \\
{[\text { mean } \pm S D]}\end{array}$ & $\begin{array}{c}3.31 \pm 3.2 \\
{[\text { mean } \pm \mathrm{SD}]}\end{array}$ \\
\hline $\begin{array}{c}\text { When you prescribe a drug for } \\
\text { your corneal ulcer patients, what } \\
\text { percentage was resistant to initial } \\
\text { therapy }\end{array}$ & $\begin{array}{c}14.5 \pm 16.1 \\
{[\text { mean } \pm \mathrm{SD}]}\end{array}$ & $\begin{array}{c}10.9 \pm 11.6 \\
{[\text { mean } \pm \mathrm{SD}]}\end{array}$ \\
\hline $\begin{array}{l}\text { Which of the following diagnostic } \\
\text { tests do you feel is necessary prior to } \\
\text { treatment of corneal ulcers? (Check } \\
\text { all that apply) }\end{array}$ & & \\
\hline $\begin{array}{l}\text { Culture of ulcer (Scrapping and gram } \\
\text { staining of ulcer) }\end{array}$ & $12(52.2)$ & $22(68.8)$ \\
\hline $\begin{array}{l}\text { Culture of ulcer; Scrapping and gram } \\
\text { staining of ulcer; B scan. }\end{array}$ & -- & $1(3.1)$ \\
\hline $\begin{array}{l}\text { Culture of ulcer; Scrapping and gram } \\
\text { staining of ulcer; Culture of contact } \\
\text { lenses if available. }\end{array}$ & -- & $1(3.1)$ \\
\hline If resistant scrapping and gram stain & $3(13)$ & $1(3.1)$ \\
\hline None of the above & $7(30.4)$ & $4(12.5)$ \\
\hline $\begin{array}{l}\text { Scrapping and gram staining of ulcer } \\
\text { Culture of ulcer }\end{array}$ & --- & --- \\
\hline
\end{tabular}

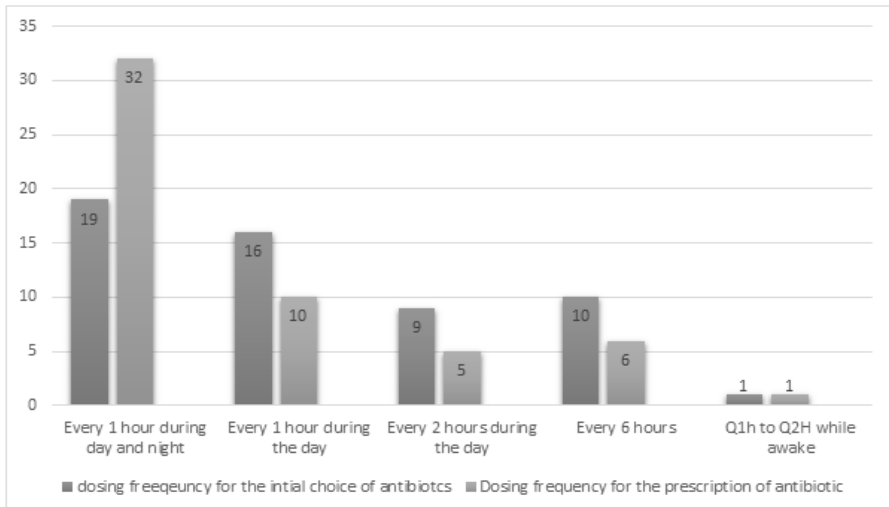

Figure 2: Shows the dosing frequency for the prescriptions of initial choice of antibiotics and prescription of antibiotics. 
Table 3: Shows the Opinions on the Need for Culturing Corneal Ulcers.

\begin{tabular}{|c|c|c|}
\hline Statements & $\begin{array}{l}\text { Corneal } \\
\text { specialist } \\
23 \mathrm{n}(\%)\end{array}$ & $\begin{array}{l}\text { Ophthalmologist } \\
\begin{array}{c}32 \\
n(\%)\end{array}\end{array}$ \\
\hline \multicolumn{3}{|l|}{$\begin{array}{c}\text { Is the pharmacy in your hospital capable of compounding antibiotic } \\
\text { preparations? }\end{array}$} \\
\hline Yes & $21(91.3)$ & $26(81.3)$ \\
\hline No & $2(8.7)$ & $6(18.8)$ \\
\hline \multicolumn{3}{|l|}{$\begin{array}{l}\text { How often you require a culture for your corneal ulcers patients? } \\
\text { (Check all that apply) }\end{array}$} \\
\hline Always & $4(17.3)$ & $10(31.2)$ \\
\hline Ulcers larger than $1.5 \times 1.5 \mathrm{~mm}$ regardless of location & $7(30.4)$ & $7(21.8)$ \\
\hline Ulcers larger than $1.5 \cdot 1.5 \mathrm{~mm}$, within the central $5 \mathrm{~mm}$ of the cornea & $10(43.4)$ & $10(31.2)$ \\
\hline \multicolumn{3}{|l|}{ All ulcers that extend to middle to deep stroma } \\
\hline Chronic ulcers & $1(4.3)$ & $1(3.1)$ \\
\hline Ulcers unresponsive to antibiotic therapy & $3(13)$ & $2(6.2)$ \\
\hline Unusual patient history or clinical features & $4(17.3)$ & 0 \\
\hline \multirow[t]{2}{*}{ Never } & $4(17.3)$ & $1(3.1)$ \\
\hline & $1(4.3)$ & $1(3.1)$ \\
\hline
\end{tabular}

Table 4: Shows the choices and dosing frequency of the antibiotics for the treatment of corneal ulcers.

\begin{tabular}{|c|c|}
\hline Statements & $\mathrm{n}(\%)$ \\
\hline \multicolumn{2}{|l|}{$\begin{array}{l}\text { What is your first choice of antibiotics to treat an advanced corneal ulcer? (Check all } \\
\text { that apply) }\end{array}$} \\
\hline Two broad spectrum antibiotics (cefazoline and gentamicin) & $39(70.1)$ \\
\hline Moxifloxacin & $5(9.1)$ \\
\hline Gatifloxacin & $2(3.6)$ \\
\hline Non-fluoroquinolone antibiotics (tobramycin or gentamicin) & $4(7.2)$ \\
\hline Cefazoline and other combinations & $5(9.1)$ \\
\hline \multicolumn{2}{|l|}{$\begin{array}{l}\text { For more severe corneal ulcers, how do you compare fourth generation fluoroquinolones } \\
\text { with dual, fortified, broad-spectrum antibiotics }\end{array}$} \\
\hline Fourth generation fluoroquinolones are as effective as fortified antibiotics & $11(19.6)$ \\
\hline $\begin{array}{l}\text { Fourth generation fluoroquinolones are better more efficacious compared to fortified } \\
\text { antibiotics. }\end{array}$ & $8(14.3)$ \\
\hline Fourth generation fluoroquinolones are less effective & $36(64.3)$ \\
\hline
\end{tabular}

Our study results reported that $89 \%$ of the surveyed ophthalmologist start with antibiotics for the treatment of corneal ulcers which is a finding in agreement with studies published in developing countries. ${ }^{27-29}$ In our study about $60 \%$ of the all respondents' states that they would use fluoroquinolones for the treatment of mild corneal ulcers (Moxifloxacin $39.3 \%$ followed by Gatifloxacin 12.5\%) Similar results were reported by Park J et al. where $55.4 \%$ of the respondents used Moxifloxacin. ${ }^{28}$ Similarly, another study from 4 states in USA reported that newer fluoroquinolone antibiotics. ${ }^{18,29}$ However, a study by Ariana et al. corneal specialists reported that only $16 \%$ of the subjects used fluoroquinolone. ${ }^{29}$ These results demonstrated the good availability and effectiveness of antibiotics. In accordance with other studies, our heights of using fluoroquinolone antibiotics might be due to most effective, availability, toxicity profile and resistance to organisms. ${ }^{29}$

In our study for the treatment of advanced corneal ulcer $70.1 \%$ of the respondents would prefer to use 2 broad spectrum fortified antibiotics as the first choice which is similar to previous studies in USA where clinicians used fortified antibiotics as their initial treatment. ${ }^{28,29}$ In the present study, $17.3 \%$ of the corneal specialist always required a culture of corneal ulcers from the patients compared to general ophthalmologists (31.2\%). These results were completely opposed to results of Park J et al. where the author reported that $12.3 \%$ of cornea specialists while $6.4 \%$ of non-cornea specialists always required cultures for corneal ulcers. ${ }^{28}$ According to our study, a significant variation was found among cornea specialist and general ophthalmologist in the importance of using a culture diagnostic test of corneal keratitis as cornea specialists were more likely to do so than general ophthalmologist for ulcers larger than $1.5 \times 1.5$ $\mathrm{mm}$ regardless of location (30.4\% vs $21.8 \%$ ). Likewise, a study by Park J et al. reported that significant difference was found between corneal and non-corneal specialists regarding the use of cultures. ${ }^{28}$ In fact, previous studies reported that cornea specialists were more knowledgeable in treatment of specific diseases as they have gone through this particular area more thoroughly. Additionally, other studies demonstrated the lack of availability of microbial culturing facilities and in the case of persistent large ulcers usually referred to a specialist. ${ }^{14,28,29}$ Certainly, the importance of culturing is well documented in the literature. It was reported that 
culturing is essential to correctly identify the etiology of infectious ulcers and to detect the specific causative organism which would help to determine the antibiotic sensitivity. ${ }^{30}$

This work showed that $64.3 \%$ of the respondents perceived that fourthgeneration fluoroquinolones were less effective in comparison to fortified, broad-spectrum antibiotics for the treatment of more severe corneal ulcers. Additionally, more number of ophthalmologists, irrespective to specialty, were interested in using two broad spectrum antibiotics such as cefazoline and gentamicin for the treatment of advanced corneal ulcer. These results were consistent with previous studies ${ }^{22,28}$ where participants reported that fortified antibiotics were effective for the treatment of corneal ulcers. However, other studies reported that the effectiveness of drug therapy is mainly dependent on the clinical response to a particular drug, as well as the results from the diagnostic testing through a culture of corneal ulcers.

\section{CONCLUSION}

In conclusion, our results showed that the management of corneal ulcers differs from specialists to general ophthalmologists. All the respondents agreed on prescribing two broad spectrum antibiotics to treat advanced corneal ulcers. Although for mild corneal ulcers, most of the respondents preferred to use fluoroquinolones such as Moxifloxacin and Gatifloxacin. However, most of the respondents believed that fourth generation fluoroquinolones were less effective in comparison to fortified, broadspectrum antibiotics. Future studies with a larger sample size are needed to investigate the effectiveness and prescribing patterns in this area is essentially important.

\section{ACKNOWLEDGEMENT}

The authors of this study thank full to all the respondents of this study for providing their support to carry out the study.

\section{CONFLICT OF INTEREST}

The authors declare no conflict of interest.

\section{ABBREVIATIONS}

SD: Standard deviation; SPSS: Statistical package for social science; MRSA: Methicillin-resistant Staphylococcus aureus; WHO: World Health Organization.

\section{REFERENCES}

1. Whitcher JP, Srinivasan M. Corneal ulceration in the developing world-a silent epidemic. British Journal of Ophthalmology. 1997;81(8):622-3.

2. Whitcher JP, Srinivasan M, Upadhyay MP. Corneal blindness: A global perspective. Bulletin of the World Health Organization. 2001;79:214-21.

3. Matoba AY, Harris DJ, Mark DB, Meisler DM. American Academy of Ophthalmology Cornea/External Disease Panel, Preferred Practice Patterns Committee. Blepharitis. American Academy of Ophthalmology, San Francisco, CA. 2003.

4. Arffa RC, Grayson M. Grayson's Diseases of the Cornea. Mosby Incorporated; 1997.

5. Cao $Y$, Zhang W, Wu J, Zhang H, Zhou H. Peripheral ulcerative keratitis associated with autoimmune disease: Pathogenesis and treatment. Journal of Ophthalmology. 2017;2017.

6. World Health Organization. Guidelines for the management of corneal ulcer at primary, secondary and tertiary care health facilities in the South-East Asia region. WHO Regional Office for South-East Asia; 2004.
7. Garg P, Rao GN. Corneal ulcer: Diagnosis and management. Community Eye Health. 1999;12(30):21.

8. Ibrahim YW, Boase DL, Cree IA. Epidemiological characteristics, predisposing factors and microbiological profiles of infectious corneal ulcers: The Portsmouth corneal ulcer study. British Journal of Ophthalmology. 2009;93(10):1319-24.

9. Upadhyay MP, Karmacharya PC, Koirala S, Shah DN, Shakya S, Shrestha JK, et al. The Bhaktapur eye study: Ocular trauma and antibiotic prophylaxis for the prevention of corneal ulceration in Nepal. British Journal of Ophthalmology. $2001 ; 85(4): 388-92$.

10. Dart JK, Stapleton F, Minassian D. Contact lenses and other risk factors in microbial keratitis. The Lancet. 1991;338(8768):650-3.

11. Bourcier T, Thomas F, Borderie V, Chaumeil C, Laroche L. Bacterial keratitis: Predisposing factors, clinical and microbiological review of 300 cases. British Journal of Ophthalmology. 2003;87(7):834-8.

12. Sharma S, Srinivasan M, George C. The current status of Fusarium species in mycotic keratitis in South India. Indian Journal of Medical Microbiology. 1993;11(2):140.

13. DeKaspar HM, Koss MJ, He L, Blumenkranz MS, Ta CN. Antibiotic susceptibility of preoperative normal conjunctival bacteria. American Journal of Ophthalmology. 2005;139(4):730-3.

14. Park SH, Lim JA, Choi JS, Kim KA, Joo CK. The resistance patterns of normal ocular bacterial flora to 4 fluoroquinolone antibiotics. Cornea. 2009;28(1):68-72.

15. .Constantinou M, Daniell M, Snibson GR, Vu HT, Taylor HR. Clinical efficacy of moxifloxacin in the treatment of bacterial keratitis: A randomized clinical trial. Ophthalmology. 2007;114(9):1622-9.

16. Hyndiuk RA, Eiferman RA, Caldwell DR, Rosenwasser GO, Santos Cl, Katz $H R$, et al. Comparison of ciprofloxacin ophthalmic solution $0.3 \%$ to fortified tobramycin-cefazolin in treating bacterial corneal ulcers. Ophthalmology. 1996;103(11):1854-63.

17. Austin A, Lietman T, Rose-Nussbaumer J. Update on the management of infectious keratitis. Ophthalmology. 2017;124(11):1678-89.

18. Hsu HY, Nacke R, Song JC, Yoo SH, Alfonso EC, Israel HA. Community opinions in the management of corneal ulcers and ophthalmic antibiotics: A survey of 4 states. Eye and Contact Lens. 2010;36(4):195-200.

19. McLeod SD, DeBacker CM, Viana MA. Differential care of corneal ulcers in the community based on apparent severity. Ophthalmology. 1996;103(3):479-84.

20. Eurosurveillance Editorial Team. CDC publishes report on antibiotic resistance threats in the United States for the first time. Euro surveillance: Bulletin Europeen Sur Les Maladies Transmissibles: European Communicable Disease Bulletin. 2013;18(38).

21. Hanet MS, Jamart J, Chaves AP. Fluoroquinolones or fortified antibiotics for treating bacterial keratitis: Systematic review and meta-analysis of comparative studies. Canadian Journal of Ophthalmology. 2012 ;47(6):493-9.

22. Suchecki JK, Donshik P, Ehlers WH. Contact lens complications. Ophthalmology Clinics of North America. 2003;16(3):471-84.

23. Loh K, Agarwal P. Contact lens related corneal ulcer. Malays Fam Physician 2010;5(1):6-8.

24. Reddy S, Tajunisah I. Contact lens-related infectious keratitis in Malaysia. Annals of Ophthalmology (Skokie, III.). 2008;40(1):39-44.

25. Hooi SH, Hooi ST. Culture-proven bacterial general hospital. Med J Malaysia. 2005;60(5):614-23.

26. Khuu T, Denial A. Contact Lens-Related Corneal Ulcer: A Teaching Case Report Optometric Education. 2011;37(1)

27. Gangopadhyay N, Daniell M, Weih L, Taylor HR. Fluoroquinolone and fortified antibiotics for treating bacterial corneal ulcers. British Journal of Ophthalmology. 2000;84(4):378-84.

28. Park J, Lee KM, Zhou H, Rabin M, Jwo K, Burton WB, et al. Community practice patterns for bacterial corneal ulcer evaluation and treatment. Eye and Contact Lens. 2015;41(1):12-8.

29. Austin A, Schallhorn J, Geske M, Mannis M, Lietman T, Rose-Nussbaumer J Empirical treatment of bacterial keratitis: An international survey of corneal specialists. BMJ Open Ophthalmology. 2017;2(1):e000047.

30. Lin A, Rhee MK, Akpek EK, Amescua G, Farid M, Garcia-Ferrer FJ, et al. Bacterial Keratitis Preferred Practice Pattern®. Ophthalmology. 2019;126(1):P1. 